\title{
Special issue dedicated to Founding Editor George Rozvany
}

\author{
Ming Zhou ${ }^{1}$ (D) Gregoire Allaire ${ }^{2} \cdot$ Gengdong Cheng $^{3} \cdot$ Jianbin Du $^{4} \cdot$ \\ Matthew Gilbert $^{5} \cdot \mathrm{Xu} \mathrm{Guo}^{6} \cdot$ James Guest $^{7} \cdot$ Raphael Haftka $^{8} \cdot$ Alicia Kim $^{9}$. \\ Thomas Lewinski $^{10}$ • Kurt Maute ${ }^{11}$ - Julian Norato ${ }^{12}$ - Niels Olhoff ${ }^{13}$. $^{14}$ \\ Glaucio H Paulino $^{14}$ • Tomasz Sokol ${ }^{10}$ • Michael Wang ${ }^{15} \cdot$ Ren-Jye Yang $^{16}$. $^{10}$ \\ Byeng Dong Youn ${ }^{17}$
}

Received: 13 September 2016 / Accepted: 14 September 2016/Published online: 11 October 2016

(C) Springer-Verlag Berlin Heidelberg 2016

This special issue is a collective effort from the Guest Editors and contributors to pay tribute to Professor George Rozvany, our Founding Editor, who passed away in July 2015. As the editorial team mourned George's passing, they collectively decided to organize a special issue to honor him. George founded this journal with Dr. Jaroslaw Sobieski in 1989, and was running the journal as Editor-in-Chief with highest dedication until his death. He had a highly productive and long research life.

Ming Zhou

zhou@altair.com

Altair Engineering, Irvine, CA, USA

2 École Polytechnique, Paris, France

3 Dalian University of Technology, Dalian, China

4 Tsinghua University, Beijing, China

5 University of Sheffield, Sheffield, UK

6 Dalian University of Technology, Dalian, China

Johns Hopkins University, Baltimore, USA

8 University of Florida, Gainesville Florida, USA

9 University of California, San Diego California, USA

10 Warsaw University of Technology, Warsaw, Poland

11 University of Colorado, Boulder, USA

12 University of Connecticut, Storrs, USA

13 Aalborg University, Aalborg, Denmark

14 Georgia Institute of Technology, Atlanta, USA

15 Hong Kong University of Science and Technology, Clear Water Bay, Kowloon, Hong Kong

16 Ford Motor Company, Dearborn Michigan, USA

17 Seoul National University, Seoul, South Korea
Due to limited volume of a single issue we limited the scope to topology optimization, George's \#1 research focus, and only invited authors who worked with him closely in the last few years of his life. The Guest Editors naturally formed out of review editors who had been working with George on the journal closely. It is quite certain that we only included a small subset of researchers who were close to George. We apologize to those who would have wanted to be included in this special issue. If you are one of them, we encourage you to add a note to one of your papers in the near future to dedicate to George Rozvany.

George's contributions in research, to this journal and to our research community were outlined in the Obituary published in October 2015 pp 633-634. We are once again paying tribute to him as a giant of our field. His legacy will live on. For his remembrance we include below two emails from George during the last weeks of his life. They show that our research community and the SMO journal were still occupying his mind even during the last days of his life.

Email from George on June 10, 2015:

Dear all, please communicate this massage to other ISSMO members. I have not written earlier because the medical professor, who is directing my treatment, wanted to cure me on time for the congress. Unfortunately some complications arose in recent day, which would make it too dangerous for me to fly to Sydney for a few days.

If anybody mentions my contributions to structural optimizations, these include:

1.) Setting up some foundation of topology of optimization with Prager (1977)

2.) Founding and editing SMO with Jarek (1989)

3.) Founding ISSMO (1991) 
4.) Doing some basic work on SIMP (1990) with Ming Zhou

Wishing all the best for the congress, George

\section{Email from George on June 29, 2015 weighing in on SMO scope:}

Dear Silvia and Ming,

I have read with interest the recent debate on the scope of SMO, although it looks that some RE's just want to show that they have an active interest in the journal.

Since I am getting some treatment every day, which leaves me little energy for many hours work (wie einst), I am asking Ming explicitly to forward the message below to all RE's and above, because I do not have here the list of their email addresses. But um Gottes Willen do not forward the top part. I am writing some words in German as a joke, because here I have to listen to German, or rather Bavarian all day and night, so it is becoming my Muttersprache.

Cheers, George

Dear RE's and above,

Sorry for missing the Sydney congress, but I had some health problems.

I have read with interest the recent debate on the scope of SMO. I wrote this text in the journal mostly in 1989, and we have made only a few changes since (e. g. including fluids).

It appears that the present scope is fairly effective in getting us a good Impact Factor (1.974 for 2014, increasing almost every year for a decade). Journals that accept all types of optimization (e.g. Eng. Optim.) have a low IF and a very small number of pages per year. I mostly object to papers for SMO that do not have structural or fluids optimization, such as papers dealing with electrical circuits or electromagnetic fields, traffic engineering, economic problems, pipeline nets or small changes to some minor algorithm without structural or fluids example in them (I was helping my son Chistopher with his micro- and macro-economics studies, with lots of optimization problems, but they would be out of scope in SMO).

Ming is right: e. g. if a company successfully marketing real estate started selling hamburgers also, this may not be good for its balance sheets, unless they have some top experts in the hamburger field. In the case of SMO, we do not have experts on electrical problems. However, your emails contain many useful ideas, which we will carefully consider.

With best wishes for the rest of the summer, George

Below are personal notes from the contributing guest editors of this special issue:

Grégoire Allaire: George had a very strong and fascinating personality. I remember well our first encounter: he was challenging the young researcher that I was, back in 1992, but in the same time was extremely generous in his help and advises. George was very much interested in mathematical aspects of topology optimization, which is a testimony of his broad scientific scope and pluri-disciplinary vision of the field of structural optimization.

Gengdong Cheng: Immediately after I completed my work on solid elastic plate optimization in 1980, George quickly grasped the inherent similarity between elastic and plastic optimum designs and invited Niels Olhoff, John Taylor and I jointed his research work on optimum plastic plate design. Our joined paper reveals that the least weight is furnished, in the limit, by a grillage-like continuum consisting of a dense system of ribs of infinitesimal spacing and uniform depth. This work bridged the long standing research on Michell truss, grillage-like continuum by Prager and Rozvany and many others with the new study on solid bending plate optimization. Since then, George and I had academic discussions from time to time. He managed to find funds to financially support several important international conferences on structural optimization. I was among lucky ones benefited from the generous supports of these conferences and had the fortune to work with George on growing ISSMO society from its early stage.

Jianbin Du: I have known George for about one decade, and is very grateful to him for very interesting discussions during international conferences and for the affordable costs to young members of ISSMO for participation in the ISSMO world congresses.

Matthew Gilbert: George Rozvany had an incredible knack of incisively cutting to the essence of a problem, and of identifying simple examples to explain complex concepts. This proved to be an incredibly powerful means of moving on the whole field of structural optimization. Thus when finalizing a paper on truss layout optimization I often thought "how would George explain this aspect?", or, more generally, "what will George think of this work?". Due to his interest in layout optimization I normally got to find out quickly, either by email or at the next conference - invariably receiving a very thoughtful and useful critique. Although passionate about truss layout optimization and classical Michell structures, George frequently expressed scepticism about their practical usefulness. However, 
in a paper contained in this special issue it is shown that truss layout optimization methods can usefully be applied in the fast growing area of design for additive manufacture (3D printing); hopefully George would have appreciated this.

James Guest: I distinctly remember the first time that I met George. I was a fresh Assistant Professor and had the honor of speaking in the same session as him at the 11th AIAA/ISSMO MAO Conference in Portsmouth, Virginia. Following our presentations, we had a lively conversation about regularization and analytical solutions in topology optimization, and about this journal. Since then my respect and admiration for George, and his contribution and tireless dedication to our field, have continuously grown. I will miss greatly our conversations and email exchanges on topics ranging from algorithmic details, to design philosophy, to this journal that he so deeply loved, and I am utterly grateful for having had the opportunity to know and befriend him.

$X u$ Guo: I first learned about George and his work when I came across his book "Optimal design of flexural systems: beams, grillages, slabs, plates, and shells" during my Ph.D. study. I was deeply impressed by the originality, rigor and completeness of his work at that time and dreamed that one day I could have the opportunity to work with him. This came true when I tried to clarify the existence of symmetric global optimal solution for a symmetry optimization problem which was first investigated by George in 2010, one of his legacies for our research field. We had many discussions on this topic and I was marveled once again at his sharpness and his capability to go to the heart of the problem with a depth of insight that is of immense beauty. Our collaboration finally led to a joint research project supported by both Hungary and China research foundations by end of 2014. Sadly, George will not join in the discussions any more. I will continue this work that was by large shaped by him, which I think is the best way for me to cherish the memory of George.

Raphael Haftka: By organizing international meetings, founding the society (ISSMO) and founding this journal, SMO, George Rozvany had a more profound impact on my career than any other person. ISSMO and SMO enabled me to start collaborations with like-minded researchers all over the world, and it allowed me to do much better research as a result. I also learned from him about the working of this journal, and I hope that I am carrying on the job of Editor-in-Chief in his spirit. Along the way, I have also enjoyed very much my personal communications with him, as besides being a first rate researcher, he was also one of the most amazingly vibrant person I have ever met.

Alicia Kim: George sat down in his usual first row having just given his keynote as the first talk of the conference. I was next, my very first conference presentation at the Australiasian structural optimization conference in Sydney in 1998. I had read his papers before and I was looking forward to hearing him in person but I could hardly concentrate on his keynote as I knew I had to walk up that podium right after. I looked up and I saw George's intense attention to my presentation and of course, the first to ask a question as soon as my well-rehearsed talk came to an end. I honestly do not remember how I answered his questions or how I came down that podium for that matter. I do clearly remember, however, that I was standing outside several hours later as George had found me to discuss my research results. He was very kind and encouraging, not to mention his insightful and helpful suggestions. I was delightfully surprised by how approachable and engaging he was. Since this first conference, George and I had many encounters by emails and at regular conferences all around the world. $\mathrm{He}$ always welcomed good scientific discussions and was generous in sharing his knowledge and scientific insights. As I reflect on the times with George and the significant impact he had on my life, I am reminded of our last conversation in the shuttle bus heading to the airport after the WCSMO conference in Orlando. I will never forget his most flattering and encouraging words as we discussed our respective research in uncertainties in topology optimization. I am saddened to think this was our last ever conversation and the loss is greatly felt in all aspects of our research community. But his legacy will continue through ISSMO, SMO journal, WCSMOs and of course, his pioneering contribution to science and engineering.

Tomasz Lewinski: Since 1960’ George was present at the most important Polish scientific meetings concerning solid and structural mechanics. The list of his Polish friends and coauthors is long, to mention here professors: Zenon Mróz, Witold Gutkowski, Stefan Jendo and the late Jacek Bauer. Thanks to his kind invitation, I spent 2 years from 1992 to 1993 as an Alexander von Humboldt fellow, at his Research lab at Essen Uni. There I made my first contributions on expanding Michell truss classes in collaboration with George. Most of the solutions started as hypotheses from George, then formulated and proven by me mathematically. His passion for topology optimization had profound influence on my research focus. Our collaboration continued until his sudden passing away in Summer 2015.

Kurt Maute: I was a "fresh" PhD student when I first met Georg Rozvany in 1994 at WCSMO-1. It was an amazing event at which George created a welcoming and open atmosphere for established and junior researchers. How special this event was and ISSMO in general is I noticed only later when attending other conferences. George Rozvany was not only an outstanding researcher in the field of mechanics and topology optimization, he also was an energetic leader of our 
community who instilled a culture of egality and inclusiveness. I will miss the lively and sharp discussions I had with George.

Julian Norato: Since my first encounters with George as a novice investigator and SMO author, to the last as Review Editor of SMO, I always admired him for his indefatigable passion for our field. George exuded this passion, and was always eager to engage in incisive and insightful conversations with aspiring and established scholars alike, whether in person or through the manuscript review process. For those of us working in topology optimization, George was a fundamental constant of sorts. He leaves us with an enduring legacy: his outstanding accomplishments in research and his unwavering dedication to our community through his beloved SMO. We, the SMO community, have a duty to carry this torch that he lit.

Niels Olhoff: I am much indebted to Prof. George Rozvany for having benefited from very inspiring collaboration and coauthorship, and we have been very close friends both personally and scientifically for more than five decades.

Glaucio H. Paulino: George was a most inspirational person ... charismatic, enthusiastic, humble, approachable, and always willing to share his vast knowledge. I met him too many times to count on this brief write-up and thus I decided to elaborate just on our first and last meetings. I vividly remember that I first met George in 2005 during the WCSMO 6 in Brazil (Rio de Janeiro). At that time I had the impression that he was a walking encyclopedia of optimization and engineering science. Our last meeting was during the week of June 13th, 2014, when we co-organized the Advanced School on "Topology Optimization of Structures and Continua - Computational Aspects and Background" which was held at the CISM (International Center for Mechanical Sciences) palace in Udine, Italy. This was a memorable event, which brought together several colleagues and students who were in attendance. Although George left, his notable influence, remarkable contributions and celebratory legacy will remain with us forever.

Tomasz Sokol: I met Professor George Rozvany during the EngOpt 2010 conference. We connected immediately because of joint scientific interest and also a similar sense of humor. Our cooperation on Michell structures started a little earlier, in 2009. Since then we exchanged hundreds of emails, often several emails per day. We met many times at various conferences and used the opportunities to discuss our research problems. One of the greatest adventures of my life includes a 3-month visiting scholarship in Budapest in 2014. I met with George almost every day for long discussions on research and joint papers. He had an incredible ability to create simple examples which beautifully explained the complexities and subtleties of structural topology optimization. It was during my stay in Budapest I became a close friend of George in a personal way. I often visited him at his large house in Solymár, an idyllic village on the outskirts of Budapest. I still vividly remember the thrill when entering his attic office first time, impressed by piles of hand written research notes and an amazing collection of great books. We spent many productive hours there... George's passing came as a shock to me as we were still working on a paper with daily exchanges a few short months back. It was an honor for me that I was part of his life in his final years. I owe him so much and he will always remain in my memory.

Byeng Dong Youn: Our beloved George was a great character who left many footprints in the society of optimisation. The footprints provide the significant impact on those who knew him and will follow his footprints in the future. Among all, the International Society of Structural and Multidisciplinary Optimisation (ISSMO) that he helped create and organise will stand as lasting monuments of his vision for outstanding group of colleagues, students and scholars. Herein I wrote a review article titled "A Comprehensive Survey on Topology Optimisation of Phononic Crystals" to note treasured memories with George.

Michael Wang: I got to know George relatively late in his career, and he showed great openness for new ideas and new developments. At an occasion when I was introducing the level set method, he commented that the idea just presented by "this young fellow" seemed somehow familiar to him and it might be interestingly useful. He always held his high standard for rigor and completeness, a quality characteristic of a great scholar. He will be missed dearly by many "young fellows" in the field that he cared and nurtured very much in his life.

Ren-Jye Yang: George's contribution and impact on Structural and Multidisciplinary Optimization are tremendous and well known worldwide. Other than technical contributions, the most impressive thing to me is that he is so unassuming, so accessible and considerate, and easy to get along with. He has given me confidence in my earlier career in the area of design optimization. In addition, George has an excellent memory. He always recognizes me even though we do not see each other often. George is a well respectable leader and we will definitely miss him dearly for a long time.

Ming Zhou: George was my mentor and close friend for almost three decades. I attended his funeral held on August 26, 2015 at a beautiful church in the serene village Solymár on the outskirts of Budapest. I want to share part of my speech at the funeral to honor George: I want to highlight four personal observations about George's remarkable integrity, morality, curiosity and passion for research exploration, and selfless community service. As I mentioned earlier, George was my 'Doctorvater' 
back in Essen between 1988 and 1992. But long before I received my doctor degree, George had already fully accepted me as an equal research partner. This leads to my first observation-George had exhibited highest level of scholarly integrity, he never leaves a due research credit to peers unmentioned, including from those who worked for him. George and I had co-authored over 40 research papers during the 9 years we worked together at Essen University. I would say that George often gave me more credit than I deserved, placing me as first author for some important papers. Over the past 27 years George and I had kept close relationship, though we lived almost half an earth apart since 1998 when I moved to Los Angeles. Since a long time we have regarded each other as the closest friend in professional life. We had frequent email exchanges, often even daily, on SMO journal issues and other broad topics ranging from research, local and world politics, philosophical perspectives, and things small and big in life... Let me finish on a high spirit - today we are here to mourn, and to share our grief over losing a close friend. But let's not forget that we are also here to celebrate the remarkable life George had lived, and the extraordinary legacy he had created. It is the more remarkable that he was able to live a fully vigorous life as a researcher, a visionary leader and a caring father to his young son Christopher at the remarkable age of 84 until the very end. Let's also take the moment to reflect on being among the lucky ones whose lives had been touched by this remarkable man. We know that George's soul will rest in peace, and his legacy will continue through all of us.

\section{Guest Editors}

Gregoire Allaire, Gengdong Cheng, Jianbin Du, HaeChang Gea, Matthew Gilbert, Xu Guo, James Guest, Raphael Haftka, Alicia Kim, Thomas Lewinski, Kurt Maute, Julian Norato, Niels Olhoff, Glaucio H Paulino, Tomasz Sokol, Michael Wang, Ren-Jye Yang, Byeng Dong Youn, Ming Zhou 